AIAA 2003-3765

Aeroheating Thermal Model Correlation for Mars Global Surveyor (MGS) Solar Array

Ruth M. Amundsen and John A. Dec NASA Langley Research Center Hampton, VA

Lt. Benjamin E. George United States Air Force Kirtland Air Force Base Albuquerque, NM

$36^{\text {th }}$ AIAA Thermophysics Conference 23-26 June 2003

Orlando, Florida 


\title{
AEROHEATING THERMAL MODEL CORRELATION FOR MARS GLOBAL SURVEYOR (MGS) SOLAR ARRAY
}

\author{
Ruth M. Amundsen, John A. Dec \\ National Aeronautics and Space Administration \\ Langley Research Center \\ Hampton, VA 23681-2199 \\ Lt Benjamin E. George \\ United States Air Force \\ Kirtland Air Force Base \\ Albuquerque, NM 87111
}

\begin{abstract}
$\underline{\text { ABSTRACT }}$
The Mars Global Surveyor (MGS) Spacecraft made use of aerobraking to gradually reduce its orbit period from a highly elliptical insertion orbit to its final science orbit. Aerobraking produces a high heat load on the solar arrays, which have a large surface area exposed to the airflow and relatively low mass. To accurately model the complex behavior during aerobraking, the thermal analysis needed to be tightly coupled to the spatially varying, time dependent aerodynamic heating. Also, the thermal model itself needed to accurately capture the behavior of the solar array and its response to changing heat load conditions. The correlation of the thermal model to flight data allowed a validation of the modeling process, as well as information on what processes dominate the thermal behavior. Correlation in this case primarily involved detailing the thermal sensor nodes, using as-built mass to modify material property estimates, refining solar cell assembly properties, and adding detail to radiation and heat flux boundary conditions. This paper describes the methods used to develop finite element thermal models of the MGS solar array and the correlation of the thermal model to flight data from the spacecraft drag passes. Correlation was made to data from four flight thermal sensors over three of the early drag passes. Good correlation of the model was achieved, with a maximum difference between the predicted model maximum and the observed flight maximum temperature of less than 5\%. Lessons learned in the correlation of this model assisted in validating a similar model and method used for the Mars Odyssey solar array aeroheating analysis, which were used during onorbit operations.
\end{abstract}

\section{INTRODUCTION}

The Mars Global Surveyor (MGS) Spacecraft launched in November of 1996 and arrived at Mars in September 1997. The initial orbit was highly elliptical, with an apoapsis of 54,026 km and a 45-hour period. Aerobraking was used to slow the spacecraft and decrease the orbit altitude to allow insertion into a final science orbit. Aerobraking is the process of skimming the spacecraft through the planetary atmosphere at periapsis, decreasing its speed and thus lowering apoapsis. This method saves substantially on the amount of fuel that must be used to achieve the science orbit. The aerobraking effort was originally planned to take four months to bring the orbit apoapsis to $450 \mathrm{~km}$. Early in the aerobraking, aerodynamic pressure caused one of Surveyor's two solar panels to bend backward slightly. The panel in question had been damaged shortly after launch. This event led to a pause in aerobraking and eventually a more conservative approach toward aerobraking, to put less stress on the damaged solar panel. Drag passes were designed to remain higher in the atmosphere than originally planned, thus decreasing the pressure load on the solar arrays but substantially increasing aerobraking duration. Aerobraking in this reduced fashion continued until March 1999, when the spacecraft was placed in the final science orbit.

The solar panels constitute the main drag on the spacecraft, and as low-mass "wings" they bear the brunt of aeroheating. The duration of aerobraking is often critical, because of high mission costs during that period, and because the duration of aerobraking affects the final science orbit achieved. The Mars Odyssey mission was to use a similar mission plan as MGS, with solar arrays bearing the brunt of aerobraking. Thus it was important to fully understand the MGS mission performance. In particular, it was important to determine the thermal behavior of the solar arrays, since they were the limiting factor in aerobraking. If more aggressive aerobraking could be used (i.e., deeper cuts into the atmosphere on each pass), it would bring down the total time and cost for the Odyssey mission, 
as well as improving the ability to control the final science orbit. MGS flight data was used to correlate a thermal model of the solar arrays, to ensure that the behavior during aerobraking was fully quantified. Then, this information was used in the thermal analysis of Odyssey's aerobraking which ultimately affected mission planning.

Because of the discovery of the damaged solar panel which led to the mid-mission change in MGS aerobraking operations, only the first 15 passes were done in the original flight corridor at relatively high atmospheric densities with a comparatively high aeroheating environment. At the start of the aerobraking phase of the mission, the mission plan was to progressively lower the aerobraking altitude due to uncertainties in the density of the Mars atmosphere. Since correlation of the thermal model to high aeroheating environments was desired, the first 14 passes, which experienced fairly benign environments, were not used and pass 15 was the first one considered for correlation.

\section{THERMAL MODEL DEVELOPMENT}

The thermal methods have been described in detail in an accompanying paper ${ }^{1}$, but enough will be described here to understand the driving factors in correlating the model. A thermal model of the spacecraft assembly was needed in order to capture the radiative environment of the solar arrays. Shading and view factors from the spacecraft helped determine the initial steady-state temperature of the solar array, as well as defining the solar and planetary flux environment that affect temperatures during a drag pass. This model captured only geometry and external surface properties for both the spacecraft and solar array. The orientation of the spacecraft with relation to the planet and sun was included in the telemetry data received from MGS.

For the detailed thermal solution, a full thermal model was developed for the solar array only. The solar arrays were mounted on gimbals with a low thermal conductance to the rest of the spacecraft, which minimized the conductive effect of the spacecraft on the array. The view factors to the spacecraft as well as solar and planetary fluxes from the radiation model were applied to the solar array model. This method allowed much more detail to be captured in the solar array thermal model without sacrificing solution time by having to include spacecraft elements in that model. Since the extent of damage to the solar array on the $-Y$ side of the spacecraft was unknown, only the $+Y$ array was modeled with the analytically determined temperatures from that array being correlated to flight thermocouple data received in the telemetry.

\section{$\underline{\text { Radiation model }}$}

The radiation model of the spacecraft and the $+\mathrm{Y}$ solar array was developed in Thermal Desktop ${ }^{2}$. A view is shown in Figure 1 (arrows are used to indicate view angles to planet and Sun). This model was used to calculate view factors from the solar array to deep space, and also to calculate solar and planetary fluxes. View factors to space are shown in Figure 2.

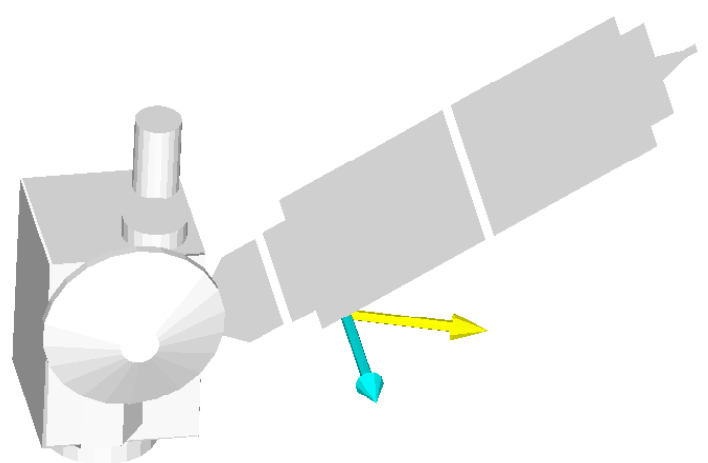

Figure 1. Radiation model of spacecraft/solar array.

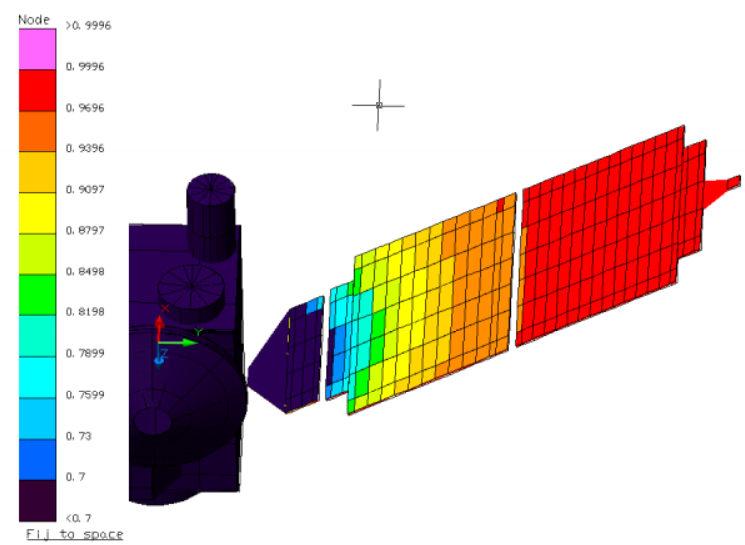

Figure 2. View factors to space from solar array.

\section{Thermal Model}

The full 3D thermal model was created in MSC/PATRAN ${ }^{3}$. This was done for two reasons. One was that existing FORTRAN code would allow simple inclusion of the aeroheating fluxes in PATRAN. The other was that the structural analysis of thermal stresses would be easily accomplished using existing methods. Normally, it is not more efficient to develop two models. However, in this case a time constraint of finishing the correlation before it was needed for Mars Odyssey on-orbit operations drove the use of existing, easily adapted methods. The radiation model in Thermal Desktop was necessary since orbital capabilities do not exist within MSC/PATRAN.

The solar array was mounted to the spacecraft at a gimbal, and had a magnetometer mounted at the outside 
tip. The array was a sandwich construction using graphite polycyanate facesheets with an aluminum honeycomb core. In places where structural connections were made, the facesheets were reinforced with doublers and the aluminum core density was increased. The solar cells were mounted over more than $90 \%$ of the surface on one side. Since the thermocouples that were used to correlate were in locations where coverage by solar cells is complete, it was decided to approximate the solar cell coverage as $100 \%$ to simplify modeling. During the drag passes the solar cell side was oriented away from the direction of flight, so that the bare graphite side, often referred to as the "hot" side, received the aerodynamic heating.

The solar array was modeled in PATRAN as five distinct layers, as shown in Figure 3. Each layer was modeled with plate elements, except for the aluminum core, which was modeled with solid elements. The layers were spaced apart, so that they could be connected via a contact conductance. This value could be varied to account for the adhesives used between the layers. Also, it accounted for the reduced contact area between the facesheets and honeycomb core. The solar cell layer was made up of a combination of materials, as described below. The Kapton sheet between the solar cell layer and graphite facesheet was $0.002 "$ thick $(0.051 \mathrm{~mm})$. The facesheets were M55J/RS-3, 0.0075" thick $(0.19 \mathrm{~mm})$. The aluminum honeycomb core was $1.0 "$ thick $(25.4 \mathrm{~mm})$. The film adhesive used between the core and facesheets was M1025A. The finite element mesh on the facesheets was customized to take the thermal sensor locations into account.

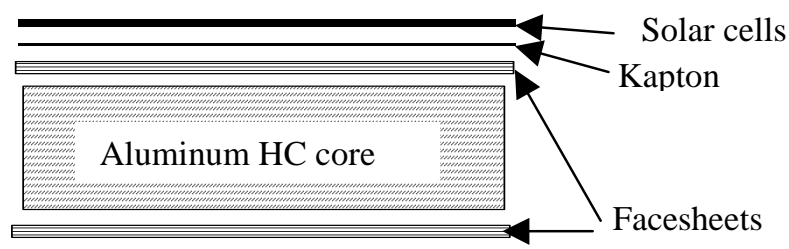

Figure 3. Layup of solar array.

The solar cell layer consisted of the following, from the outside in: a 0.005" glass coversheet, a layer of DC93500 adhesive (0.003" thick), the solar cells themselves, a metal backing to the solar cells, and a layer of CV2568 adhesive that held the cells down to the Kapton sheet. The solar cells were silicon on the outboard section of the array, GaAs on the inboard section, .008" thick. The overall thickness of this layer was $0.022 "(0.5 \mathrm{~mm})$. The properties of this layer were calculated as a weighted average of those five materials. The roughly $1 \mathrm{~kg}$ of wiring for the solar cells on each section was added to this layer as a smeared mass. The effective properties were a specific heat of
$807 \mathrm{~J} / \mathrm{kg}$ and a density of $3508 \mathrm{Kg} / \mathrm{m}^{3}$ for the GaAs panel and $2402 \mathrm{~kg} / \mathrm{m}^{3}$ for the silicon cell panel.

White paint was used over portions of the hot surface, and this was included in both the radiation model in Thermal Desktop and the radiation boundary conditions of the PATRAN model. These lower absorptivity regions on the edges and inboard corners of the array are shown in Figure 4 on the radiation model. The purpose of the paint was to provide a lower absorptance for the solar flux and allow a lower temperature for the outer portions of the array. The pattern was chosen to correspond with the areas with the highest aeroheating flux, thus helping keep them within their thermal limits. Another modification included in the model was local thickening of the Kapton sheet in the highest heating areas. At the inboard array corners, the Kapton was laid up in layers to augment the thickness so that more thermal mass was available to absorb the heating. This was included in the model by using a spatial field for the facesheet thickness, as well as changing the sheet thickness for all areas thickened with doublers. This is illustrated in Figure 5. On the solar cell side, the different optical properties of the two solar cell types were also included in both models.

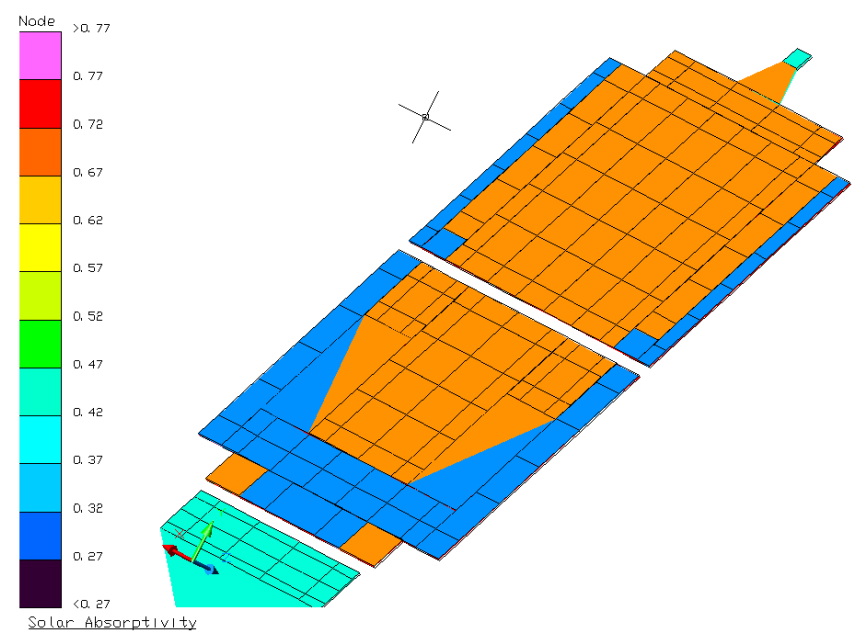

Figure 4. White paint on hot side facesheet $(\alpha)$.

Other parts included in the model were the hinges and magnetometer. The hinges were included as simple flat plates that correctly captured the mass of the hinge as well as the contact area on the array. The magnetometer mass was lumped over its contact area at the outermost tip of the array.

All material properties (except density and emissivity) were included as functions of temperature. 


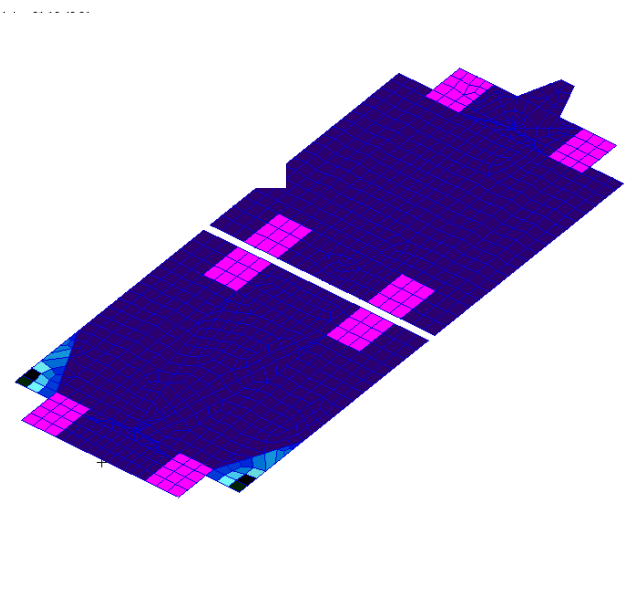

Figure 5. Thickness definition on hot side facesheet (m).

The mass of the overall model was verified by a comparison with the as-built mass from flight assembly records. The model did not include the drag flaps, and the as-built mass of only the modeled portion was roughly $26 \mathrm{~kg}$. The mass of the total thermal model was $23 \mathrm{~kg}$, for an error of roughly $11 \%$. This was not unreasonable considering the approximations within the model, and the fact that some components mounted on the solar arrays were not modeled if they were known to be far enough from any thermocouple not to affect sensor results. Since the model was too light, it was expected to lead to conservatively high temperature predictions. Several of the densities were varied during the correlation process to ascertain their effects on the model performance. The $23 \mathrm{~kg}$ mass is for the final correlated model.

\section{Boundary Conditions}

Boundary conditions included contact conductance between layers, convection, radiation, aeroheating, and solar and planetary fluxes. The contact between layers was calculated as the effective conductance due to the adhesive thickness. These calculations and the overall total effective conductance through the thickness of the entire array are shown in Table 1. The total calculated value of $19 \mathrm{~W} / \mathrm{m}^{2} \mathrm{~K}$ was somewhat higher than the value from correlation of a 2-node model in early ground testing $\left(0.01 \mathrm{~W} / \mathrm{in}^{2} \mathrm{C} \text {, or } 15.5 \mathrm{~W} / \mathrm{m}^{2} \mathrm{~K}\right)^{4}$. However, it is difficult to compare the two values for several reasons. In the ground test, local effects and sensor mass could affect the correlated value.

Radiation through the core was treated as a separate radiation boundary condition in this modeling, whereas in the 2-node model it was included in the effective conduction value. Also, this effective conduction is shown only for the majority of the array, not for local regions such as the areas with doublers. The contact conductance values were varied during correlation, especially the most uncertain value, which was that of the facesheet to the core. The values shown are for the final correlated model.

Table 1. Effective Conduction through Array Thickness

\begin{tabular}{|c|c|c|c|c|}
\hline Layer & $\begin{array}{l}\text { Thick- } \\
\text { ness }\end{array}$ & Mat'l & $\begin{array}{l}\text { Added } \\
\text { layer }\end{array}$ & $\begin{array}{l}\text { Eff. } \\
\text { conduct- } \\
\text { ance } \\
\left(\mathbf{W} / \mathbf{m}^{2} \mathbf{K}\right)\end{array}$ \\
\hline $\begin{array}{l}\text { Face- } \\
\text { sheet to } \\
\text { core } \\
\text { (each } \\
\text { side) }\end{array}$ & .0075" & $\begin{array}{l}\text { M55J/ } \\
\text { RS-3 }\end{array}$ & $\begin{array}{l}0.003 " \\
\text { adhesive } \\
\text { layer, in } \\
\text { contact } \\
\text { over } 1 \% \\
\text { of area } \\
\text { (honey- } \\
\text { comb } \\
\text { cell } \\
\text { walls) }\end{array}$ & 52 \\
\hline Kapton & .002" & Kapton & & 2755 \\
\hline $\begin{array}{l}\text { Solar } \\
\text { cells }\end{array}$ & $\begin{array}{l}.0075 " \\
(\mathrm{GaAs}) \\
.008 " \\
(\mathrm{Si})\end{array}$ & $\begin{array}{l}\text { Solar } \\
\text { cells }\end{array}$ & $\begin{array}{l}0.006 " \\
\text { CV } \\
2568 \\
\text { bond }\end{array}$ & 822 \\
\hline Core & $1 "$ & $\begin{array}{l}\mathrm{Al} \\
\text { honey- } \\
\text { comb }\end{array}$ & & 79 \\
\hline $\begin{array}{l}\text { Total } \\
\text { conduct- } \\
\text { ance }\end{array}$ & & & & 19 \\
\hline
\end{tabular}

The radiation boundary conditions included both internal and external radiation. Radiation through the aluminum core, from one facesheet to another, was applied. The view factors from the Thermal Desktop spacecraft model were applied as fields in the appropriate regions, by mapping the viewfactors into the PATRAN model, as shown in Figure 6. View factors to both space and the spacecraft were included. Space temperature was fixed at $3 \mathrm{~K}$ during the exoatmospheric portion of the analysis, and then was allowed to vary to simulate the Martian atmosphere/space combination during the drag pass. 


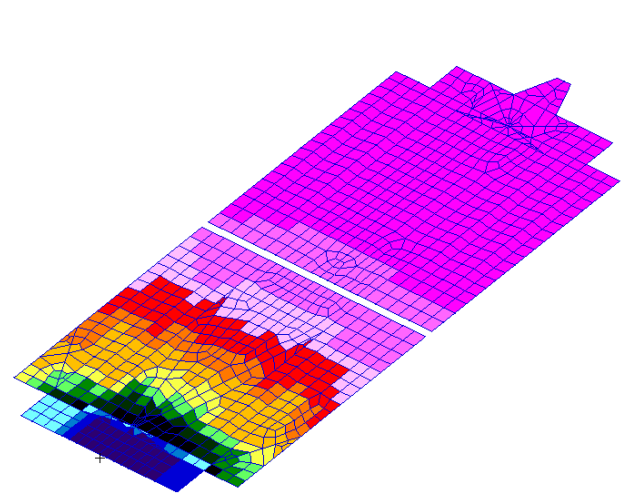

$\sum_{x}^{Y}$

Figure 6. Viewfactors to space from solar cell side.

The aeroheating was calculated using a two-step process. First, the atmospheric density experienced by the spacecraft was calculated using accelerometer data from the spacecraft. Then using the atmospheric density and the velocity relative to the atmosphere, the aeroheating on the solar array was calculated. The correlation of the atmospheric density to the accelerometers was made using Direct Simulation Monte Carlo (DSMC) which modeled the interaction of atmospheric particles with the entire spacecraft. The relation between the density and the acceleration is captured in the equation:

$m a=\frac{1}{2} c_{d} \rho V^{2}$

where $m$ is the known mass of the spacecraft, $a$ is the acceleration due to atmospheric drag, $\mathrm{c}_{\mathrm{d}}$ is the drag coefficient determined using DSMC, $\rho$ is the atmospheric density, and $\mathrm{V}$ is the velocity relative to the atmosphere. The acceleration due to drag was calculated at time intervals throughout the drag pass directly from the flight accelerometer data. Similarly, the velocity relative to the atmosphere was calculated at the same time intervals using the orbital trajectory. Then, for each time interval, the aerothermal heating over the surface of the solar array was calculated for the given atmospheric density and relative velocity, once again using DSMC techniques. This relationship is defined by the following equation:

$q=\frac{1}{2} C_{H} \rho V^{3}$

where $\mathrm{q}$ is the aerothermal heating, $\mathrm{C}_{\mathrm{H}}$ is the heating coefficient at a given point on the array calculated using DSMC, $\rho$ is the atmospheric density, and V is the velocity relative to the atmosphere. The heating coefficient is a function of density, velocity, and orientation relative to the velocity. Due to the large computational time needed to perform the DSMC calculations, some simplifying assumptions were made. The effects on $\mathrm{C}_{\mathrm{H}}$ due to changes in velocity and orientation through the pass are negligible compared to the changes in density. Thus the calculations were made at a constant, average velocity for the nominal orientation. DSMC calculations were performed at prescribed intervals of density encapsulating the range of expected flight conditions, and interpolation was used to determine the heating coefficients over the surface of the array for the calculated density. Then, using equation (2), the aerothermal heating over the surface of the array was calculated at time intervals spanning an entire aerobraking pass. These aeroheating calculations were performed using MATLAB with an aeroheating flux array exported as the product for use in the PATRAN model.

The aeroheating flux array was a function of both physical position on the array, and time within the drag pass. The aeroheating was interpolated in both time and space onto the PATRAN model on the entire exterior. User-developed FORTRAN was used within PATRAN to accomplish this interpolation. The mapping at one time point, on the hot side, is shown in Figure 7. As shown, the inboard corners of the array received the highest heating, which was the reason for localized use of white paint and thickened Kapton. Average heating on the edges of the array was taken to be $10 \%$ of the heating on the nearest point of the hot side $^{5}$.
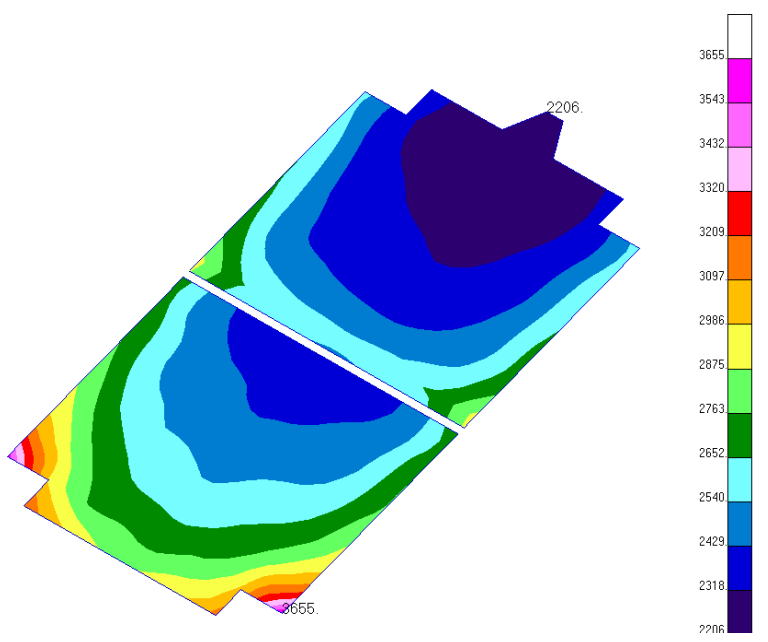

Figure 7. Aeroheating near peak during pass $15\left(\mathrm{~W} / \mathrm{m}^{2}\right)$.

The aeroheating data included incident heating only, so reflected heating needed to be calculated within 
PATRAN. The following equation was developed empirically to approximate the reflected component ${ }^{5}$ :

$$
C_{H, \text { net }}=C_{H, i}-\left[0.015+0.06 *\left(1-C_{H, i}\right)\right] *\left(T_{\text {wall }} / 300\right)
$$

Where the coefficients $C_{H}$ are defined as:

$$
C_{H}=q /\left(\frac{1}{2} \rho V^{3}\right)
$$

This calculation was carried out within the existing FORTRAN code in order to subtract that component from the incident heating.

\section{Orbital Conditions}

Initially, the model was intended to be run from a steady-state condition with a single global constant temperature. However, it became evident that the initial condition would substantially affect the transient solution. Thus, the model was run for a steady-state solution using the orbital orientation of the spacecraft just prior to initiation of aerobraking. This allowed at least an approximate gradient prediction across the array, so that the response at the start of aerobraking would be accurate. The main focus of the model was to correlate to aerodynamic heating, so many of the preaerobraking spacecraft operations that occur in the vacuum were not included. Using a steady-state temperature for the vacuum phase condition gave an accurate enough prediction of the thermal initial condition that no detailed transient in the vacuum phase was considered.

\section{INITIAL THERMAL RESULTS}

The first runs of the thermal model were done with no knowledge of the flight data, to see how close the model would be with no alterations based on post-flight knowledge. This simulates to some extent a normal thermal progression, where the initial modeling is done before flight, and there is no knowledge of in-flight performance. The results are shown plotted on the 3D model in Figure 8. The through thickness scale in this figure is exaggerated to allow the thickness to be visible. The cooling effects of the mass of the hinges, doubler areas and magnetometer can be seen. Also, the temperature difference between the hot side and solar cell side is substantial.

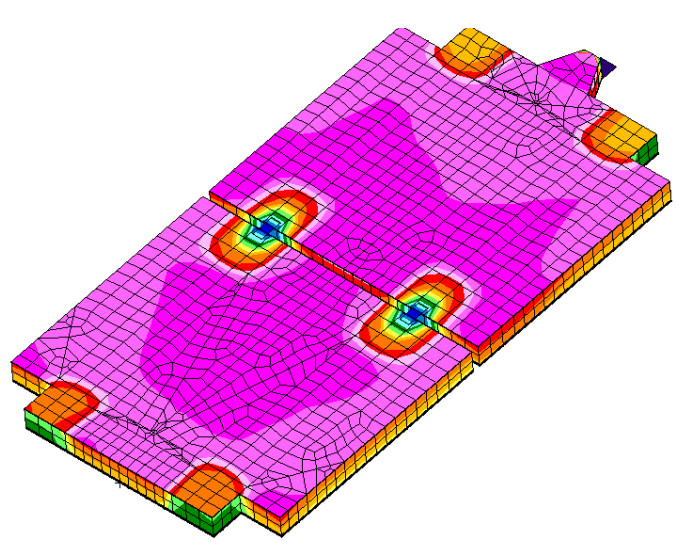

(a)

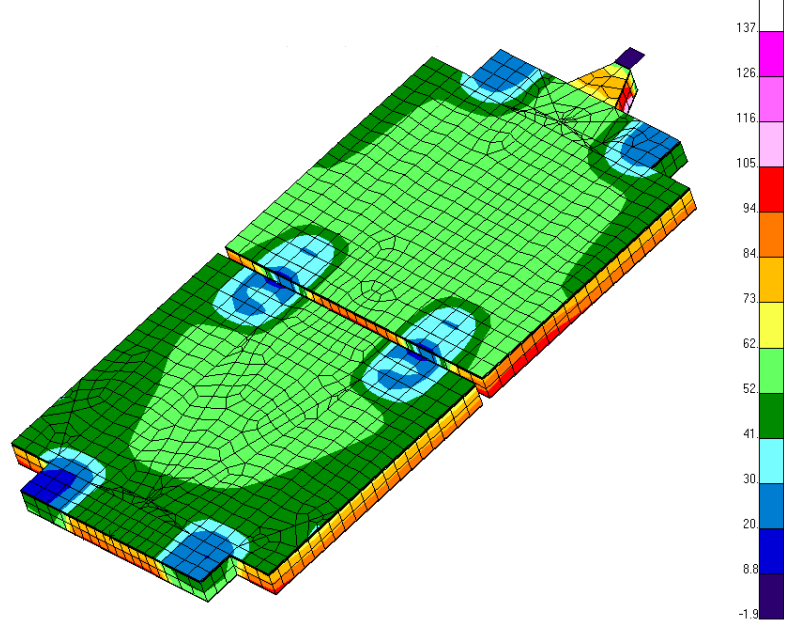

(b)

Figure 8. Initial thermal predictions for MGS solar array: (a) hot side, (b) cell side, ${ }^{\circ} \mathrm{C}$.

\section{THERMAL CORRELATION PROCESS}

The flight data consisted of thermocouple measurements for four different locations on the solar array. There were two sensors on the solar cell side, and two on the hot side. The two on the hot side were applied to the underside of the graphite facesheet, with a hole through the core and solar cell facesheet to allow the penetration. The sensors on the solar cell side were applied directly to the outer facesheet. The two hot side sensors were T211 and T213, and the cell side sensors were T210 and T212, as shown in Figure 9. In this figure only the facesheets are shown, and the throughthickness dimension is greatly exaggerated to allow visualization of the thermal sensor locations. The initial comparison to flight sensor data is shown in Figure 10. The time scale starts prior to aerobraking, and a time of 0 seconds corresponds to the peak of the pass (periapsis). This first comparison was only for the 
hot side sensors, since those defined the peak heating that can be sustained by the array and thus were most critical to correlate. Also, since the point of this model was to correlate to changes that occurred during aerobraking, the initial condition was subtracted off, and only temperature changes for both flight and the model were compared. As is evident, the sensors in the model were responding too quickly to the heating, and were getting too hot. The sensor predictions on the solar cell side followed a similar pattern, although they were somewhat closer to the flight data. The hot side sensors were over $60^{\circ} \mathrm{C}$ too hot in the model (much worse on the inboard side), and reached their peaks about 60 seconds before they should. The cell side sensors were about $30^{\circ} \mathrm{C}$ too hot in the model. The temperature difference between hot side and cold side was also too high, and occurred too quickly.

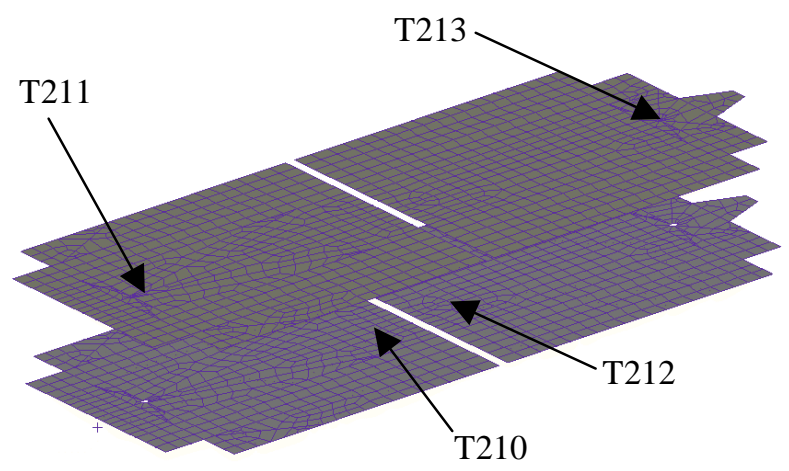

Figure 9. Flight temperature sensor locations.

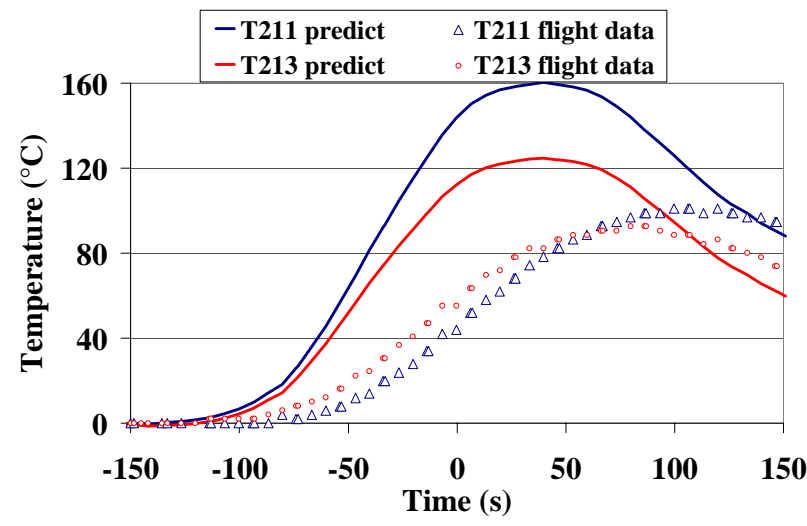

Figure 10. Initial comparison of model to flight data.

Another interesting comparison was the difference between the hot side and cell side sensors, both on the outboard and inboard panels. This illustrates where the model was off on both through thickness and lateral conduction, since the sensors were separated not only by the thickness of the panel, but also by most of the area of the panel as well. The initial comparison is shown in Figure 11. It is obvious that the temperature difference between hot side and cell side was too high, and was occurring too rapidly, in the model.

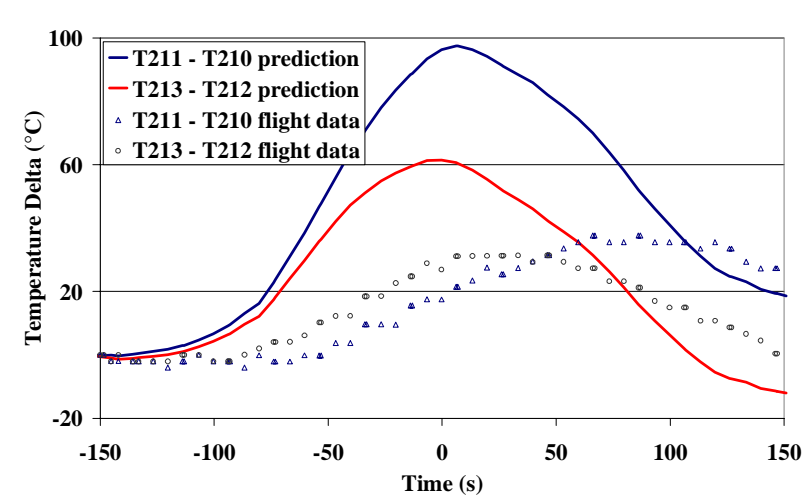

Figure 11. Initial comparison of hot-to-cell-side differences.

Several actions were taken to make the model more representative of flight. Most of these changes were additional detailing and refinements of the model. Radiation within the thermal sensor holes was added. The radiation within the holes was between the hot side facesheet and a layer of Kapton over the hole in the solar cell side. This brought the hot side thermocouple temperature down by about $2.5^{\circ} \mathrm{C}$. The solar cell properties were modified to include the metal backing, wires and other components that had not been broken out separately. This helped by about $5-10^{\circ} \mathrm{C}$. The thickness of the facesheets was increased to include the effective thickness of the adhesive, which also helped bring temperatures down slightly.

Even though the main intent of the model was only to model accurately the behavior during aerobraking, it became obvious that the initial temperature distribution was affecting the behavior. Thus, the steady state model in the vacuum phase was improved, and comparisons with flight data were done using the actual temperatures, rather than changes from an initial condition.

Radiation within the aluminum honeycomb was added, which helped by another $2^{\circ} \mathrm{C}$, but still left the inboard hot side much worse than the outboard hot side. The detail of the thermal sensors was increased, including adding adhesive under them as their connection to the face sheet, and adding wires with radiation to the enclosing hole for the hot side sensors. The optical properties for the GaAs solar cells, silicon cells and white paint were refined and detailed on both the radiation and thermal models, and run for both the steady-state initial condition and the transient model. This helped improve the difference between the inboard and outboard panels.

Myriad other minor changes were made, such as making sure all material properties were bounded over 
the thermal excursions experienced, adding radiation over the edges of the core, refining the hinges and adding damper masses. Also, many properties were varied to experiment with their effects, such as aluminum honeycomb core density, facesheet conductivity, adhesive thickness under sensors, and honeycomb core contact area. Another small change was to increase the thickness of the facesheets in the areas where white paint was applied, which is a real effect that had not been considered in the original modeling. This did help by $2.5^{\circ} \mathrm{C}$ on the sensor directly under that painted area (T211).

\section{FINAL THERMAL RESULTS}

The final corrected run to the pass 15 flight data is shown in Figure 12. The hottest thermocouple is predicted very well, and all others are conservative (i.e., prediction is somewhat too warm).

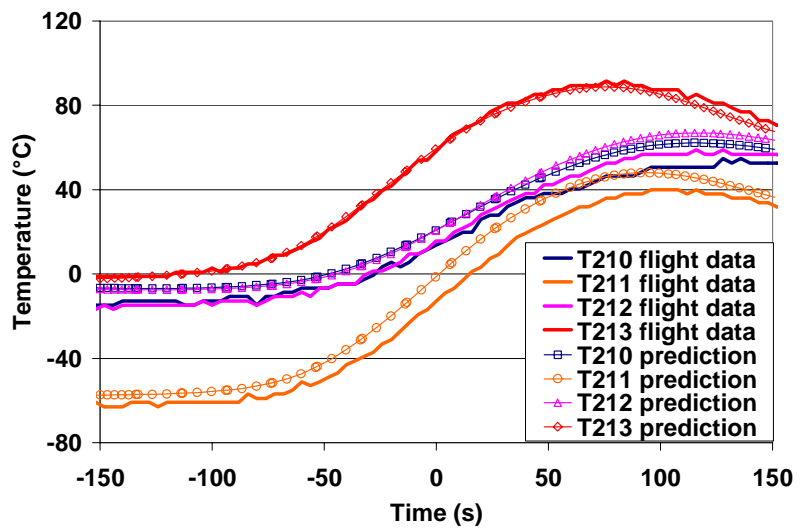

Figure 12. Final correlation, actual temperatures.

Because the intent of this model was mainly to predict the rise in temperature due to aeroheating, and not focused on the pre-aerobraking vacuum orbit phase, the correlation was also evaluated only from the point of view of temperature rise during aerobraking. To do this, the initial temperature of each sensor and prediction were removed from the data, leaving only the change from the start of aerobraking. The results of this are shown in Figure 13. All sensor responses look very good, except that the prediction for sensor T213 is rising a little too rapidly. This may be due to the low mass of the model, or to excessive conductance for the adhesive under the sensor. The hot side to cell side differences are shown in Figure 14, and these have obviously improved greatly in the correlation.

Overall quality of the model was evaluated in several ways, which are listed in Table 2. The primary measure of correlation was the change in temperature due to aerobraking. This difference in peak temperature change between model and flight, regardless of the timing, is shown in the row "Difference in peak temperature change". The worst value on a sensor was $4.4^{\circ} \mathrm{C}$. Another measure was the time difference between when peak temperature was reached between the model and flight, shown in the row "Difference in peak timing". The difference in actual peak temperature is listed next in the table; differences of about $8^{\circ} \mathrm{C}$ reflect the inaccuracy of the starting temperatures. The RMS difference in the aeroheating temperature rise was calculated, which gives a measure of the accuracy of the model over all times, not just at the peak. The worst RMS difference was $6.7^{\circ} \mathrm{C}$. The largest overall difference between prediction and flight over all time points was worst for $\mathrm{T} 211$ at $12^{\circ} \mathrm{C}$. The final row gives the error of the model as a percentage, based on the first row values (peak temperature rise). If the RMS of these is taken, it gives an overall correlation error of $3 \%$. All these measures point to a robust model that reflects in-flight performance accurately.

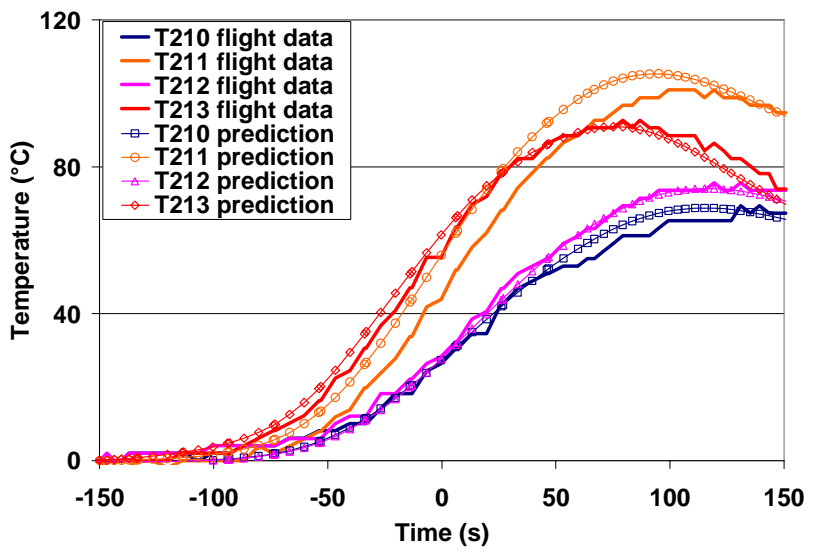

Figure 13. Final correlation, temperature change.

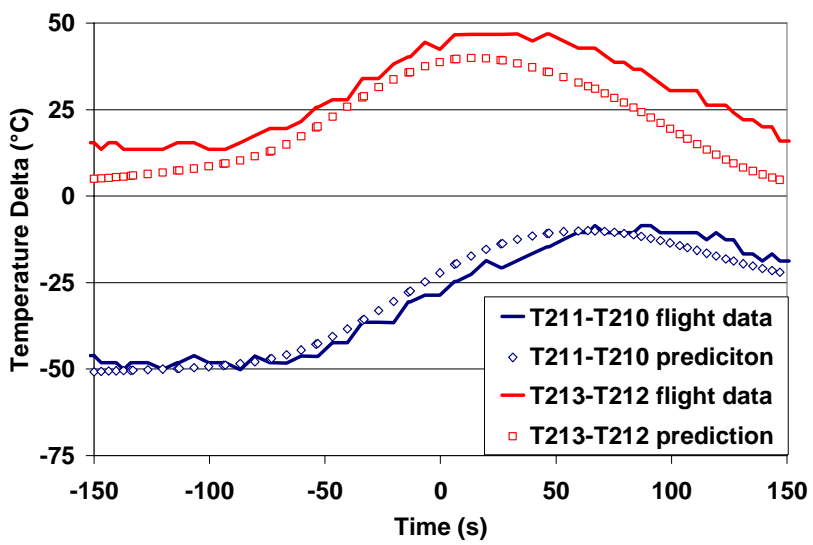

Figure 14. Temperature differences, hot to cell side. 
Table 2. Correlation Quality Measures

\begin{tabular}{|c|r|r|r|c|}
\hline & T210 & T211 & T212 & T213 \\
\hline $\begin{array}{c}\text { Difference in peak } \\
\text { temperature change } \\
\left({ }^{\circ} \mathrm{C}\right)\end{array}$ & -0.7 & 4.4 & -1.6 & -1.8 \\
\hline $\begin{array}{c}\text { Difference in peak } \\
\text { timing (sec) }\end{array}$ & -12.7 & -0.7 & -0.7 & -0.7 \\
\hline $\begin{array}{c}\text { Difference in peak } \\
\text { actual temperature }\end{array}$ & 7.5 & 8.0 & 8.0 & -2.8 \\
\hline $\begin{array}{c}\text { RMS difference in } \\
\text { temperature change } \\
\text { over time }\left({ }^{\circ} \mathrm{C}\right)\end{array}$ & 2.6 & 6.7 & 2.1 & 2.9 \\
\hline $\begin{array}{c}\text { Largest difference by } \\
\text { time point }\left({ }^{\circ} \mathrm{C}\right)\end{array}$ & 5.5 & 12.0 & 4.4 & 6.2 \\
\hline $\begin{array}{c}\text { Difference in peak } \\
\text { temperature change } \\
(\%)\end{array}$ & $-1 \%$ & $4 \%$ & $-2 \%$ & $-2 \%$ \\
\hline
\end{tabular}

After this was completed, orbits 10 and 13 were selected at random to verify the correlation, and were run with the same model. Correlation plots are shown in Figure 15 and Figure 16. The overall quality values (RMS error for peak temperature prediction) for these were $5 \%$ and $6 \%$ for pass 10 and pass 13 , respectively. In these lower aeroheating passes, the solar and planetary fluxes make up a larger proportion of the effect, so they are not expected to achieve as good a correlation.

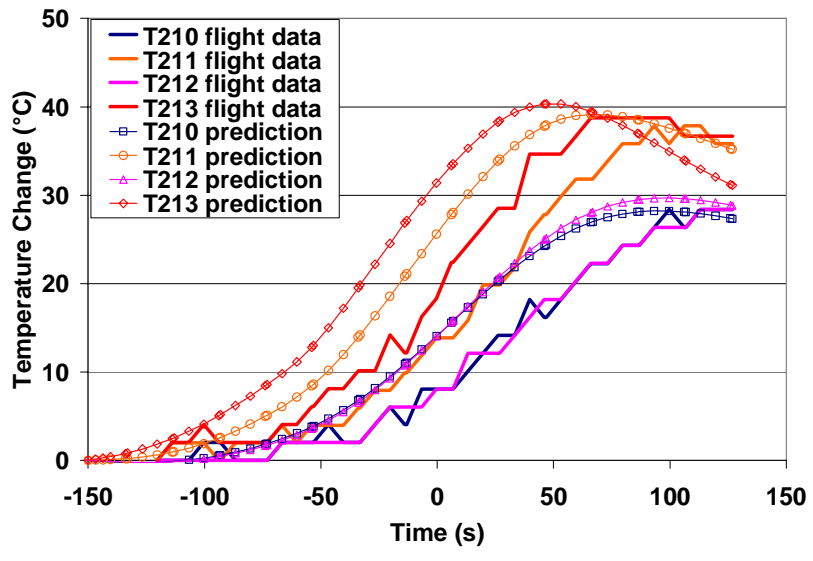

Figure 15. Correlation for Pass 10.

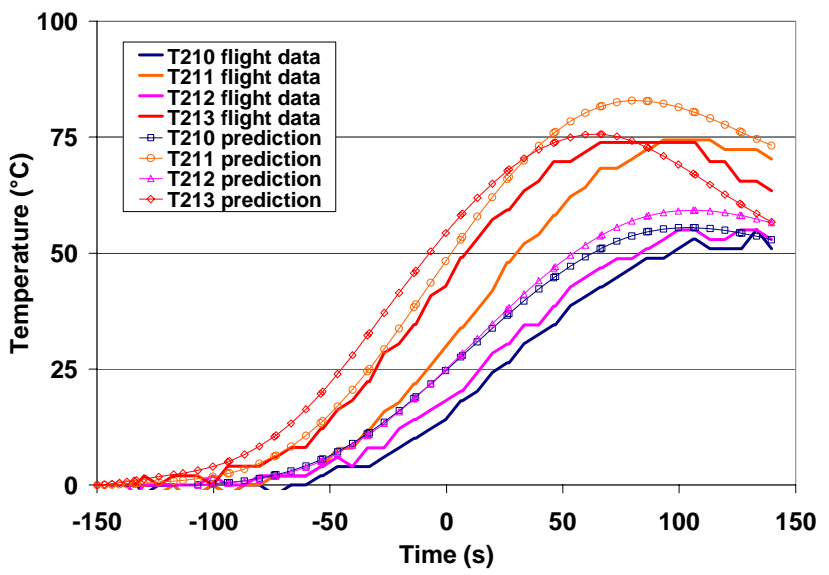

Figure 16. Correlation for Pass 13.

The 3D thermal maps of this correlated model are also useful to visualize the overall thermal condition of the array. In all of these figures, the thickness dimension is exaggerated to improve visualization. The initial predicted temperature gradient prior to the start of aerobraking is shown in Figure 17. The white painted areas are shown to be effective in cooling the inboard corners of the array, which are expected to receive the highest aeroheating fluxes. The gradient prediction at the time of peak temperature is shown in Figure 18 and Figure 19 for the hot side and cell side, respectively. The inboard corners have been effectively pre-cooled, so that they do not become the hottest parts of the array. The mass of the hinges can be shown to locally slow down temperature rise. The effects of the relatively high conductance along the facesheets, and lower conductance through the core, can be seen.

A benefit of this full 3D model is that the maximum temperature prediction for each component or material can be calculated and compared with its maximum service temperature. Since MGS had already undergone aeroheating at the time of this modeling, this capability was not of use to this program, but in general this information can be used in the design process as well as in the trajectory planning. An example is shown in Figure 20. All materials remained well within their service limits, as expected since the aeroheating levels actually experienced were much less than the design target. 


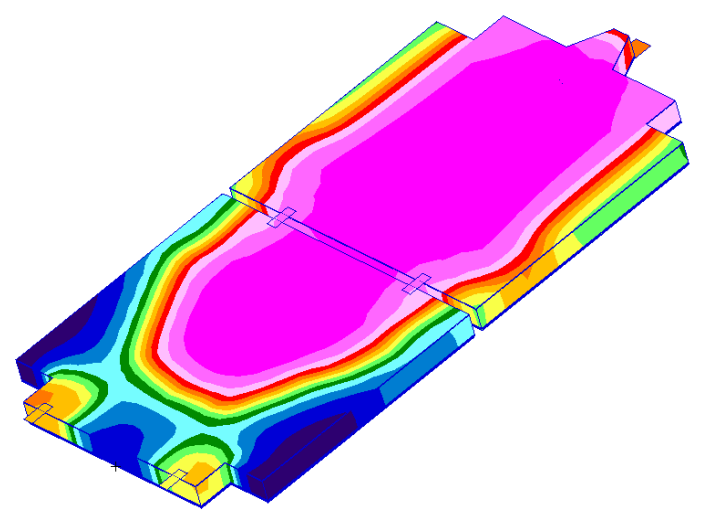

Figure 17. Thermal map prior to aerobraking $\left({ }^{\circ} \mathrm{C}\right)$.

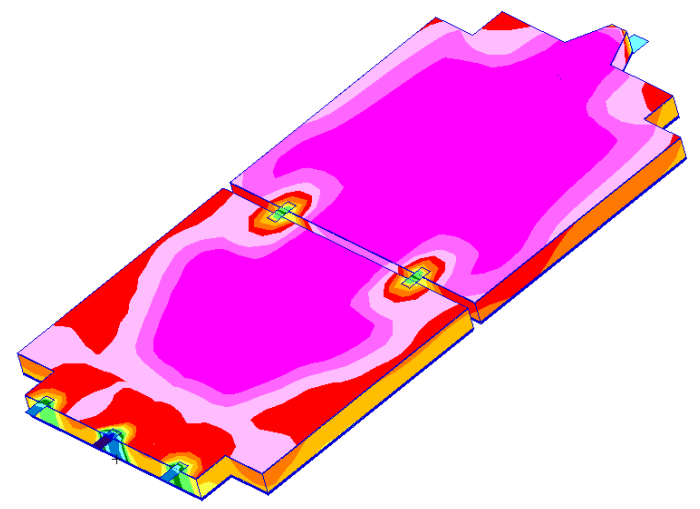

Figure 18. Final thermal map at $70 \mathrm{sec}$, hot side $\left({ }^{\circ} \mathrm{C}\right)$.

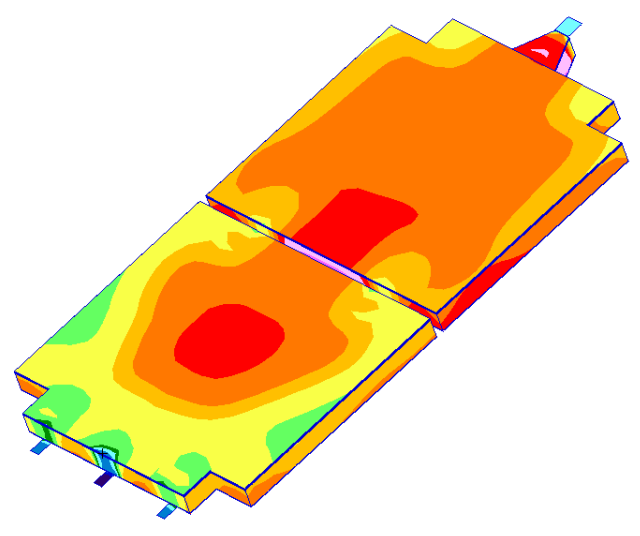

Figure 19. Final thermal map at $70 \mathrm{sec}$, cell side $\left({ }^{\circ} \mathrm{C}\right)$.
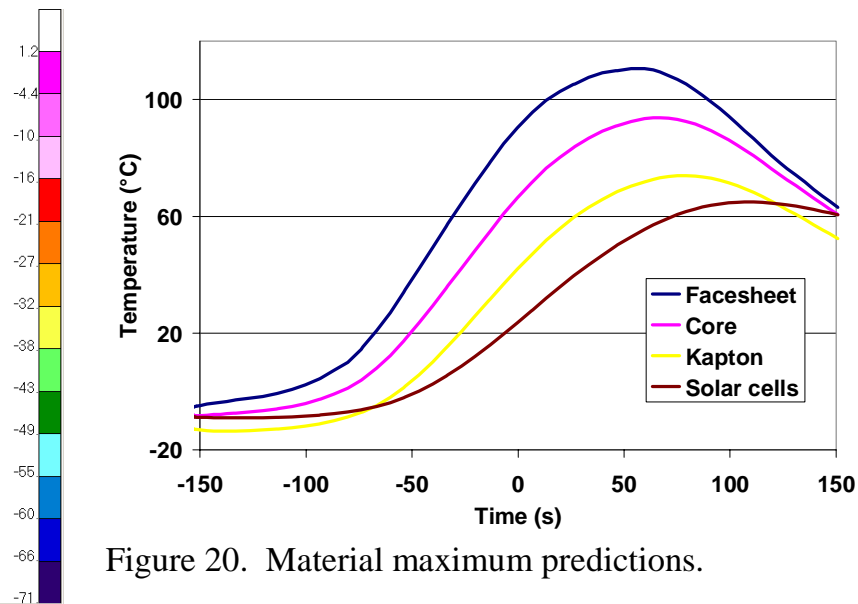

Figure 20. Material maximum predictions.

\section{CONCLUSIONS}

A full 3D thermal model of the MGS spacecraft was developed, and predictions at sensor locations were compared to the flight data. Good correlation was obtained for the highest heating pass (pass 15), as well as for two other earlier passes. A measure of correlation quality was the RMS value from four sensors of the flight-to-prediction difference in peak temperature change due to aerobraking. Using this measure, model accuracy was in the range 3 to $6 \%$. Lessons learned in the model correlation were utilized in the Mars Odyssey project thermal modeling effort. Small details such as increased mass due to paint thickness, sensor mass, and radiation through thermocouple penetrations were found to have substantial impact in achieving a correlated model. The thermal state prior to the start of aerobraking also played a large part in determining the response.

\section{ACKNOWLEDGEMENTS}

The assistance of Michael Griffin at Lockheed Martin Astronautics in providing drawings, details of the assembly, and advice is gratefully acknowledged. Thanks are due to the entire Mars Odyssey flight operations team at Langley, in particular Richard Wilmoth for help with the aeroheating calculations, Dick Powell for his support, and Bob Tolson for initiating this effort.

\section{ACRONYMS}

DSMC Direct Simulation Monte Carlo

MGS Mars Global Surveyor

RMS Root-mean-square

\section{REFERENCES}

${ }^{1}$ Dec, John A., and Amundsen, Ruth M., A Thermal Analysis Approach for the Mars Odyssey Spacecraft's Solar Array, AIAA 2003 Thermophysics Conference, Orlando, Florida, June 2003. 
2 Thermal Desktop user manual, Cullimore and Ring Technologies, Inc., Version 3.2, August 2000.

${ }^{3}$ MSC/PATRAN User Manual, MacNeal-Schwendler Corporation, Version 2000 (r2), August 2000.

${ }^{4}$ Internal memo, Lockheed Martin, "Solar Array Thermal Model", May 27, 1999 from Mike Griffin to Susan Bathras.

5 Internal NASA LaRC communication, "MGS /Odyssey LaRC Aeroheating Analysis", R.G. Wilmoth, June 21, 2001. 